\title{
$\mathrm{NH}_{3}$ 전환효율 극대화를 위한 Urea 인젝터의 분사 최적화에 관한 수치적 연구 \\ 문 성 준 ${ }^{1)} \cdot$ 조 낙 원 ${ }^{2} \cdot$ 오 세 두 ${ }^{* 1} \cdot$ 정 수 진 ${ }^{1)} \cdot$ 박 경 우 $^{2}$ \\ 자동차부품연구원 가스엔진기술연구센터' · 호서대학교 기계공학과
}

\section{A Numerical Study on the Optimization of Urea Solution Injection to Maximize Conversion Efficiency of $\mathrm{NH}_{3}$}

\author{
Seongjoon Moon $^{1)} \cdot$ Nakwon $\mathrm{Jo}^{2)} \cdot$ Sedoo $\mathrm{Oh}^{* 1)} \cdot$ Soojin Jeong ${ }^{1)} \cdot$ Kyoungwoo Park ${ }^{2)}$ \\ ${ }^{1)}$ Korea Automotive Technology Institute, 303 Pungse-ro, Pungse-myeon, Dongnam-gu, Cheonan-si, \\ Chungnam 330-912, Korea \\ ${ }^{2)}$ Department of Mechanical Engineering, Hoseo University, Chungnam 336-795, Korea \\ (Received 31 October 2013 / Revised 17 January 2014 / Accepted 20 January 2014)
}

\begin{abstract}
From now on, in order to meet more stringer diesel emission standard, diesel vehicle should be equipped with emission after-treatment devices as NOx reduction catalyst and particulate filters. Urea-SCR is being developed as the most efficient method of reducing NOx emissions in the after-treatment devices of diesel engines, and recent studies have begun to mount the urea-SCR device for diesel passenger cars and light duty vehicles. That is because their operational characteristics are quite different from heavy duty vehicles, urea solution injection should be changed with other conditions. Therefore, the number and diameter of the nozzle, injection directions, mounting positions in front of the catalytic converter are important design factors. In this study, major design parameters concerning urea solution injection in front of SCR are optimized by using a CFD analysis and Taguchi method. The computational prediction of internal flow and spray characteristics in front of SCR was carried out by using STAR-CCM+7.06 code that used to evaluate $\mathrm{NH}_{3}$ uniformity index $\left(\mathrm{NH}_{3} \mathrm{UI}\right)$. The design parameters are optimized by using the $\mathrm{L}_{16}$ orthogonal array and small-the-better characteristics of the Taguchi method. As a result, the optimal values are confirmed to be valid in $95 \%$ confidence and $5 \%$ significance level through analysis of variance(ANOVA). The compared maximize $\mathrm{NH}_{3} \mathrm{UI}$ and activation time $\left(\mathrm{NH}_{3} \mathrm{UI}\right.$ 0.82) are numerically confirmed that the optimal model provides better conversion efficiency of $\mathrm{NH}_{3}$. In addition, we propose a method to minimize wall-wetting around the urea injector in order to prevent injector blocks caused by solid urea loading. Consequently, the thickness reduction of fluid film in front of mixer is numerically confirmed through the mounting mixer and correcting injection direction by using the trial and error method.
\end{abstract}

Key words : Diesel engine(디젤엔진), Urea-SCR(요소첨가 선택적 환원촉매), Computational fluid dynamics analysis (전산유체역학), $\mathrm{NH}_{3}$ uniformity index( $\mathrm{NH}_{3}$ 농도균일도 지수), Design of experiment(실험계획법), Taguchi method (다구치법), Smaller the better characteristics(망소특성), Wall-wetting(벽류), Trial and error method(시행착오법)

*A part of this paper was presented at the KSAE 2013 Annual

Conference and Exhibition

*Corresponding author, E-mail: sdoh@katech.re.kr

\section{1. 서 론}

향후 시행될 디젤자동차의 배출가스 기준을 만족 시키기 위해서는 $\mathrm{NOx}$ (Nitrogen Oxides)저감 효율이 가장 우수한 SCR(Selective Catalytic Reduction)시스 
템의 장착이 필요하다. ${ }^{1)}$ 특히 최근에는 디젤엔진의 적용범위가 승용차로 확대됨에 따라, 낮은 부하조 건에서도 de-NOx 성능을 극대화할 수 있는 Urea$\mathrm{SCR}$ 시스템에 대한 연구가 활발히 진행되고 있다.

Urea-SCR 시스템의 환원제인 $\mathrm{NH}_{3}$ 는 $\mathrm{SCR}$ 촉매 전단에서 분사되는 Urea 수용액과 배기가스 사이 의 가수분해 및 열분해 반응에 의해 생성되기 때문 에 충분한 반응시간과 균일한 농도 분포가 필요하 다. ${ }^{2}$ 즉 $\mathrm{NH}_{3}$ 전환효율을 극대화시키기 위해서는 Urea 인젝터의 분사 조건을 최적화해야 한며, 이를 통해 SCR 시스템의 de-NOx 성능을 크게 개선할 수 있다. 한편, 수많은 경우의 수가 요구되는 최적설 계에서는 수치적 접근을 통해 예측 가능한 오차범 위 내에서 면밀히 분석하는 다원적설계최적화 $(\mathrm{MDO})$ 및 전산최적설계 $(\mathrm{CAO})$ 가 최근 널리 사용 되고 있다.

본 연구에서는 상용코드인 STAR-CCM+7.06을 통해 SCR 촉매전단의 분무유동특성을 분석하여, $\mathrm{NH}_{3}$ 전환효율에 큰 영향을 줄 수 있는 Urea 인젝터 의 주요설계변수를 선정한다. 그리고 실험계획법 (DOE)과 다구치 법의 망소특성을 통해 최적 수준을 산출하여, 개선효과를 수치적으로 검증한다. 또한, 고화된 Urea에 의한 노즐 막힘을 방지하기 위해 벽 류를 최소화시키는 방법을 제안한다.

\section{2. 수치 해석}

$\mathrm{SCR}$ 촉매전단의 분무유동특성을 파악하고자 3 차원 $\mathrm{CFD}$ 를 통한 전산모사를 수행하였다. ${ }^{3,4)}$

\subsection{SCR 촉매전단}

$\mathrm{SCR}$ 촉매전단은 Fig. 1 과 같이 배기관, Urea 인젝 터, 믹서로 구성된다. 고온의 배기가스가 배기관 내 로 유입되면, Urea 인젝터는 Urea 수용액(Urea Water Solution, UWS 을 분사하여 $\left(\mathrm{L}_{1}-\mathrm{L}_{2}\right)$, 가수분해 및 열 분해 반응으로 환원제인 $\mathrm{NH}_{3}$ 를 생성시킨다 $\left(\mathrm{L}_{3}-\mathrm{L}_{4}\right)$. 본 연구에서는 CATIA-V5와 STAR CCM+를 사용하 여 SCR 촉매전단을 모델링하였다. Mesh 모델링에 는 Polyhedral과 Prism layer를 사용하고, 수렴성을 고려하여 Volume mesh의 수를 46만 개로 최적화하 였다.

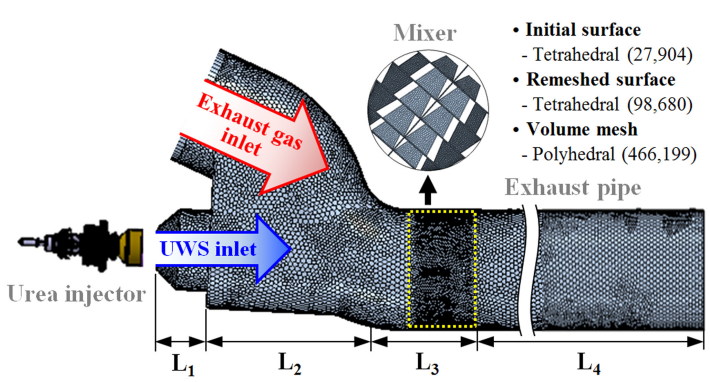

Fig. 1 Computational mesh in front of SCR for the 3-D CFD analysis

\section{2 해석 조건}

$\mathrm{SCR}$ 촉매전단의 전산모사를 위한 지배방정식은 수렴성이 우수한 Menter의 K-Omega SST(Shear Stress Transport) 난류모델을 적용하였다. 그리고 배기가 스의 유동은 Continuous phase의 Eulerian framework 를 사용하고, 배기가스 내의 여러 화학종은 Air로 가 정하였다. 한편 NEDC(New European Driving Cycle) 모드에서 엔진의 평균부하를 경계조건으로 가정하 여, 배기가스의 유동 속도와 온도를 결정하였다. Urea 수용액의 분무를 전산모사하기 위해 Dispersed phase의 Lagrangian framework가 사용되었으며, 분 무초기 Urea 인젝터 노즐 홀 끝단에서의 1 차 Droplet brake-up은 sheet 특성의 LISA(1st atomization)모델, 이후 2차 Droplet brake-up은 Bag. stripping 특성의 Reitz- Diwakar(2nd atomization) 모델을 적용하였다 (Table 1 참조). 또한 SCR 촉매전단에서 발생하는 반 응인 가수분해(Water evaporation)와 열분해반응(Urea thermolysis)도 함께 적용하였다. ${ }^{5-7)}$

\section{3 해석 결과}

초기모델의 $\mathrm{SCR}$ 촉매전단 전산모사를 수행한 결 과, 최대 $\mathrm{NH}_{3}$ 농도균일도 $\left(\mathrm{NH}_{3} \mathrm{UI}\right)$ 는 0.82 , 활성시간 $\left(\mathrm{NH}_{3} \mathrm{UI} 0.82\right)$ 은 $0.086 \mathrm{sec}$ 로 계산되며, 배기관 내 $\mathrm{L}_{3}$ 지점까지 농도균일도는 급격히 상승하다가 $\mathrm{L}_{4}$ 지점 부터 점진적으로 상승한다(Fig. 2 참조). 그리고 배 기가스와 Urea 수용액이 충돌하는 $\mathrm{L}_{2}$ 구간의 배기관 곡률부에서 압력강하가 발생한다(Fig. 3 참조). 한 편, $\mathrm{NH}_{3}$ 농도균일도는 Urea 수용액의 $\mathrm{NH}_{3}$ 전환이 배기관 내 단면에서 얼마나 균등하게 이루어졌는지 정량적으로 산출할 수 있는 척도로 식 (1)과 같이 계 
Table 1 Simulation model and numerical conditions

\begin{tabular}{|c|c|c|}
\hline \multicolumn{3}{|c|}{ Analysis model } \\
\hline \multicolumn{2}{|c|}{ Tool } & STAR-CCM+7.06 \\
\hline \multicolumn{2}{|c|}{ Boundary condition } & Implicit unsteady \\
\hline \multicolumn{2}{|c|}{ Turbulence model } & SST(Menter) K-Omega \\
\hline \multicolumn{2}{|c|}{ Max. step } & 12,000 (Iteration base) \\
\hline \multicolumn{2}{|c|}{$\begin{array}{l}\text { Continuous phase } \\
\text { (Carrier stream) }\end{array}$} & $\begin{array}{c}\text { Eulerian heat/mass transfer } \\
\text { (Suitably modified) }\end{array}$ \\
\hline \multicolumn{2}{|c|}{$\begin{array}{l}\text { Dispersed phase } \\
\text { (Dispersed element) }\end{array}$} & $\begin{array}{c}\text { Lagrangian heat } / \text { mass transfer } \\
\text { (Computational parcels, Statistical } \\
\text { approach) }\end{array}$ \\
\hline \multicolumn{3}{|c|}{ Working condition (Eulerian framework) } \\
\hline \multicolumn{2}{|c|}{ Working fluid } & Air $(\fallingdotseq$ Exhaust gas $)$ \\
\hline \multicolumn{2}{|c|}{ Temperature $\left[{ }^{\circ} \mathrm{C}\right]$} & 300 (Common) \\
\hline \multicolumn{2}{|c|}{ Mass flow rate $[\mathrm{g} / \mathrm{s}]$} & 39.6 (Common) \\
\hline \multicolumn{3}{|c|}{ Injection condition (Lagrangian framework) } \\
\hline \multicolumn{2}{|c|}{ Injection type } & Hollow cone injection \\
\hline \multicolumn{2}{|c|}{ Working fluid } & $\begin{array}{c}\text { Urea water solution } \\
\text { (urea: } 32.5 \mathrm{wt} \% \text {, water: } 67.5 \mathrm{wt} \% \text { ) }\end{array}$ \\
\hline \multicolumn{2}{|c|}{ Temperature $\left[{ }^{\circ} \mathrm{C}\right]$} & 20 \\
\hline \multicolumn{2}{|c|}{ Mass flow rate $[\mathrm{g} / \mathrm{s}]$} & 0.262 ( 5 bar $)$ \\
\hline \multicolumn{2}{|c|}{ Spray angle $\left[{ }^{\circ}\right]$} & 20 \\
\hline \multicolumn{3}{|c|}{ Droplet brake-up } \\
\hline \multicolumn{2}{|c|}{$1^{\text {st }}$ atomization } & LISA (Sheet) \\
\hline \multicolumn{2}{|c|}{$2^{\text {nd }}$ atomization } & Reitz-Diwaker (Bag. stripping) \\
\hline \multicolumn{3}{|r|}{ Reacting } \\
\hline $\begin{array}{c}\text { Water } \\
\text { evaporation }\end{array}$ & \multicolumn{2}{|c|}{$\left(\mathrm{NH}_{2}\right)_{2} \mathrm{CO}(\mathrm{aq}) \rightarrow\left(\mathrm{NH}_{2}\right)_{2} \mathrm{CO}(\mathrm{s}$ or $\mathrm{l})+6.9 \mathrm{H}_{2} \mathrm{O}(\mathrm{g})$} \\
\hline $\begin{array}{c}\text { Urea } \\
\text { thermolysis }\end{array}$ & \multicolumn{2}{|c|}{$\left(\mathrm{NH}_{2}\right)_{2} \mathrm{CO}(\mathrm{s}$ or $\mathrm{l}) \rightarrow\left(\mathrm{NH}_{3}\right)(\mathrm{g})+\mathrm{HNCO}(\mathrm{g})$} \\
\hline $\begin{array}{l}\text { Cyanic acid } \\
\text { hydrolysis }\end{array}$ & \multicolumn{2}{|c|}{$\mathrm{HNCO}(\mathrm{g})+\mathrm{H}_{2} \mathrm{O}(\mathrm{g}) \rightarrow \mathrm{NH}_{3}(\mathrm{~g})+\mathrm{CO}_{2}(\mathrm{~g})$} \\
\hline
\end{tabular}

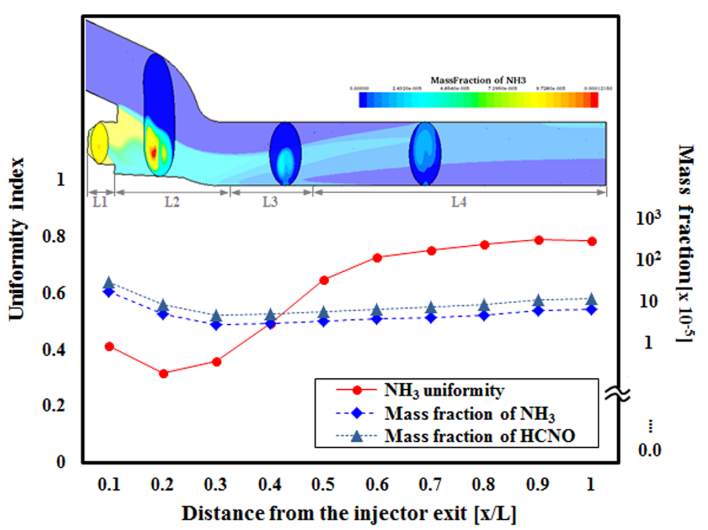

Fig. 2 Calculation result of $\mathrm{NH}_{3}$ uniformity index and mass fraction $\left(\mathrm{NH}_{3}, \mathrm{HCNO}\right)$ in front of SCR

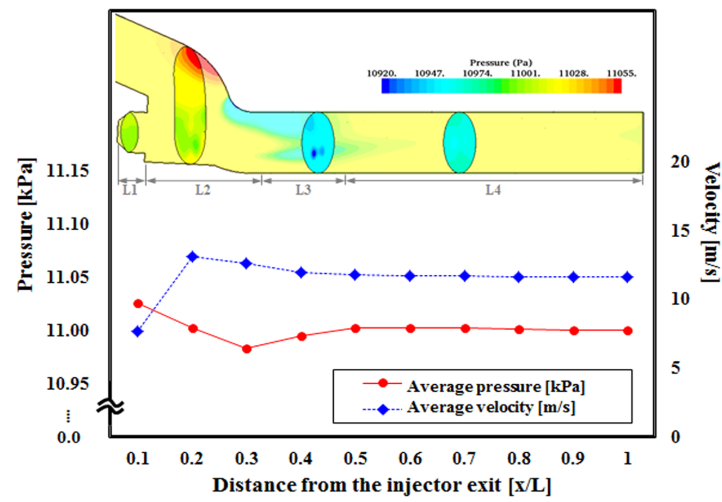

Fig. 3 Calculation result of pressure and velocity distribution in front of SCR

산된다. 이 수치가 1.0 에 가까울수록 $\mathrm{NH}_{3}$ 전환이 균 일하게 이루어져, $\mathrm{SCR}$ 촉매에서의 $\mathrm{NOx}$ 저감효율이 향상되고, $\mathrm{NH}_{3}$ slip 발생가능성이 낮아진다.

$\gamma=1-\frac{1}{2 n} \sum_{i=1}^{n} \frac{\sqrt{\left(w_{i}-w_{\text {mean }}\right)^{2}}}{w_{\text {mean }}}$

where $\mathrm{w}_{\mathrm{i}}$ : local value, $\mathrm{w}_{\text {mean }}$ : mean value, $\mathrm{n}$ : total number of measuring point

\section{4 검증}

초기모델의 전산모사 해석결과를 검증하기 위하 여 분무가시화 실험결과와 비교하였다. 분무관통길 이(Penetration length)를 비교한 결과, 배기가스와 Urea 수용액의 합류 까지는 거의 일치하고 있으며, 합류 이후 약 $8 \%$ 이하의 오차가 발생한다. 그러나 수치해석 특성상 합류 이후는 Dispersed phase 보다 Continuous phase의 영향이 지배적이며, 따라서 촉 매전단의 전산모사는 타당한 것으로 판단된다(Fig. 4 참조). 한편, 정상상태를 가정한 수치해석에서는 Urea 수용액이 분사되면, 액적 입자는 표면장력 및 관성력 차이에 의해 분열된다. 이러한 액적 분열 및 확산은 상대적인 밀도 감소를 촉진시켜 감가속도로 인한 오차가 발생한 것으로 판단된다. 또한 분무가 시화 실험은 인젝터의 압력손실과 고속카메라의 성 능에 따른 측정오차가 발생할 수 있다.

Fig. 5 와 같이 분사량을 비교한 결과, 해석 결과는 실험 대비 약 $1.5 \% \sim 9.0 \%$ 높은 분사량이 산출되며, 이는 Urea 인젝터의 노즐 끝단에서 발생하는 마찰 


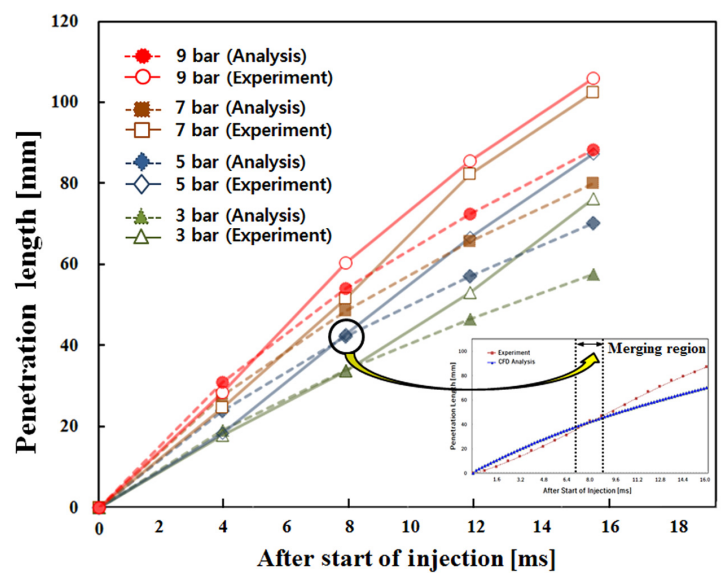

Fig. 4 Comparison of penetration length between experimental results and analysis results

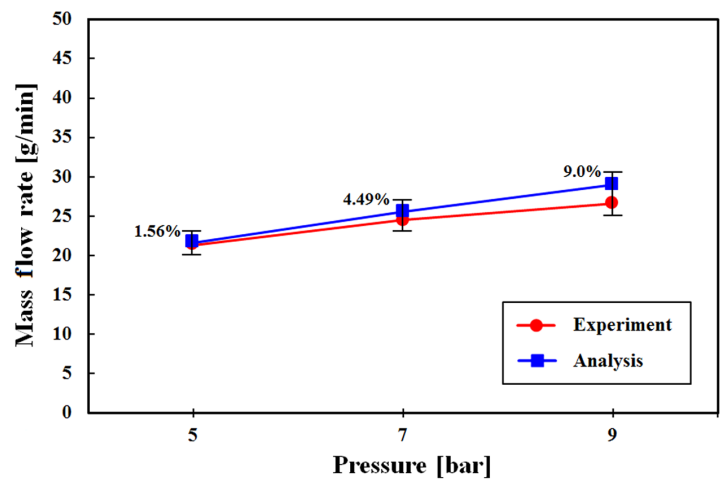

Fig. 5 Comparison of mass flow rate between experimental results and analysis results

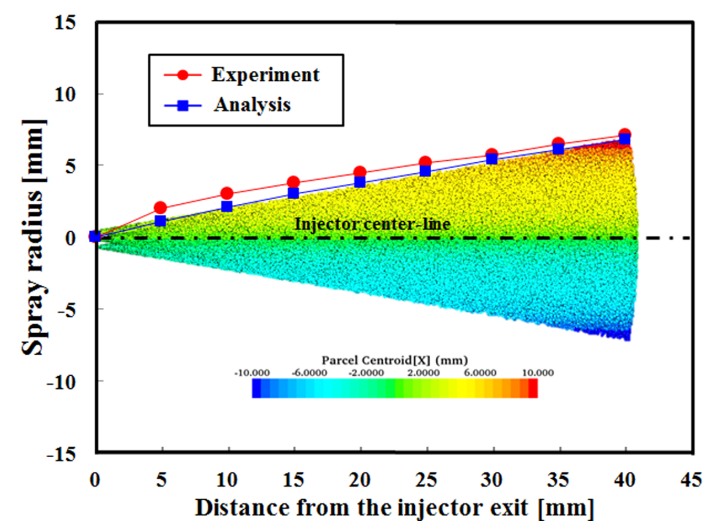

Fig. 6 Comparison of spray radius between experimental results and analysis results

이 고려되지 않았기 때문이다. 본 연구에서는 이러 한 오차를 감안하고자, 분사속도의 초기조건을 보
정하여 전산모사를 수행하였다.

Fig. 6은 분무가시화 실험을 통해 측정한 분무각 과 분무직경을 해석과 비교한 것이다. 분무압력이 5 bar일 때, 분무 이후 $8 \mathrm{~ms}$ 에서 분무각은 거의 일치하 고 있으나, 분무직경은 실험 대비 평균 $17.4 \%$ 의 오 차가 발생하였다. 한편, Urea 수용액이 배기가스와 합류되는 지점에서의 분무직경은 $4.2 \%$ 이하의 근소 한 오차가 발생하였으며, 따라서 분무해석 모델이 타당하다고 판단된다.

\section{3. 최적 설계}

$\mathrm{SCR}$ 촉매전단에서 Urea 인젝터의 주요 설계인자 에 대한 실험계획법을 처리하고, 다구치법의 망소 특성을 통해 최적해를 산출한다.

\section{1 문제 정식화}

배기가스 유동과 Urea 수용액 분무가 합류하면서 형성되는 유동접촉면의 크기와 위치는 $\mathrm{NH}_{3}$ 농도균 일도에 큰 영향을 준다. 유동접촉면의 크기가 커지 면 배기관 전단에서 $\mathrm{NH}_{3}$ 농도균일도는 증가하지만, 후단에서는 빠른 벽류 발생으로 인해 $\mathrm{NH}_{3}$ 농도균일 도가 감소할 수 있다. 유동접촉면의 위치가 배기관 내 상단에 형성되면, 배기관 전단에서 $\mathrm{NH}_{3}$ 농도균 일도는 감소하지만, 후단에서는 느린 벽류 발생으 로 인해 $\mathrm{NH}_{3}$ 농도균일도가 증가할 수 있다.

본 연구에서는 이러한 유동접촉면적의 크기와 위 치를 고려하여, 노즐 홀 개수와 직경, 분사방향과 분 사위치를 설계변수로 선정하였다(Table 2 참조). 우 선 Urea 인젝터의 노즐의 경우, 홀 개수에 따라 직경 을 감소시켜 동일 면적에서 Urea 수용액이 분사되 도록 각 수준을 결정하였다. 그리고 분사방향과 분 사직경은 배기관과 인젝터 형상에 의한 치수적인 한계범위를 벗어나지 않도록 각 수준을 결정하였다.

\section{2 실험계획법}

전술한 각 설계변수에 대한 실험계획법(DOE)을 처리하기 위해 3 인자-4수준의 $\mathrm{L}_{16}$ 직교배열법(Orthogonal array)을 선정하였다(Table 3 참조). 직교배열 법은 다양한 근사모델과의 호환성이 우수하여 실험 계획법에 널리 사용되고 있다. 
Table 2 The critical design variables and their levels

\begin{tabular}{|c|c|c|c|}
\hline $\begin{array}{c}\text { Design } \\
\text { Variables }\end{array}$ & $\begin{array}{c}\text { A: Nozzle hole } \\
\text { number/diameter }\end{array}$ & $\begin{array}{c}\text { B: Injection } \\
\text { direction }\end{array}$ & $\begin{array}{c}\text { C: Injection } \\
\text { position }\end{array}$ \\
\hline Lv. & $\begin{array}{c}\text { A: Nozzle hole } \\
\text { number/ diameter } \\
{[\mathrm{mm}]}\end{array}$ & $\begin{array}{c}\text { B: Injection } \\
\text { direction } \\
{\left[{ }^{\circ}\right]}\end{array}$ & $\begin{array}{c}\text { C: Injection } \\
\text { position } \\
{[\mathrm{mm}]}\end{array}$ \\
\hline 1 & $1 / 0.216$ & 0 & -8 \\
\hline 2 & $2 / 0.153$ & 9 & 0 \\
\hline 3 & $3 / 0.125$ & 18 & 8 \\
\hline 4 & $4 / 0.108$ & 27 & 15 \\
\hline
\end{tabular}

Table 3 Orthogonal array $\left(\mathrm{L}_{16}\right)$ the design variables and their levels

\begin{tabular}{|c|c|c|c|c|c|c|c|}
\hline No. & A & B & C & No. & A & B & C \\
\hline 1 & 1 & 1 & 1 & 9 & 3 & 1 & 3 \\
\hline 2 & 1 & 2 & 2 & 10 & 3 & 2 & 4 \\
\hline 3 & 1 & 3 & 3 & 11 & 3 & 3 & 1 \\
\hline 4 & 1 & 4 & 4 & 12 & 3 & 4 & 2 \\
\hline 5 & 2 & 1 & 2 & 13 & 4 & 1 & 4 \\
\hline 6 & 2 & 2 & 1 & 14 & 4 & 2 & 3 \\
\hline 7 & 2 & 3 & 4 & 15 & 4 & 3 & 2 \\
\hline 8 & 2 & 4 & 3 & 16 & 4 & 4 & 1 \\
\hline
\end{tabular}

\section{3 최적 수준 예측}

전술한 3 인자-4수준의 실험계획법은 다구치법의 품질특성 중 망소특성으로 접근할 수 있으며, 기대 손실을 최소화하기 위한 목적함수인 $\mathrm{S} / \mathrm{N}$ ratio (Signal to noise ratio)는 아래 식 (2)와 같다. 특성치의 가법 성을 향상시키기 위하여 $10 \log$ 를 취하고, 분산이 작을
Table 4 Simulation result associated with the experiments

\begin{tabular}{|c|c|c|c|c|c|c|c|}
\hline No. & $\begin{array}{c}\text { Max. } \\
\mathrm{NH}_{3} \\
\text { UI }\end{array}$ & $\begin{array}{c}\text { Act. time } \\
(0.82) \\
{[\mathrm{s}]}\end{array}$ & $\begin{array}{c}\text { S/N } \\
\text { Ratio }\end{array}$ & No. & $\begin{array}{c}\text { Max. } \\
\mathrm{NH}_{3} \\
\text { UI }\end{array}$ & $\begin{array}{c}\text { Act. time } \\
(0.82) \\
{[\mathrm{s}]}\end{array}$ & $\begin{array}{c}\mathrm{S} / \mathrm{N} \\
\text { Ratio }\end{array}$ \\
\hline 1 & 0.901 & 0.0915 & 2.25 & 9 & 0.884 & 0.092 & 1.64 \\
\hline 2 & 0.893 & 0.0938 & 1.87 & 10 & 0.851 & 0.085 & 0.83 \\
\hline 3 & 0.906 & 0.100 & 1.87 & 11 & 0.903 & 0.098 & 1.88 \\
\hline 4 & 0.948 & 0.105 & 2.51 & 12 & 0.943 & 0.102 & 2.70 \\
\hline 5 & 0.909 & 0.089 & 2.62 & 13 & 0.861 & 0.099 & 0.55 \\
\hline 6 & 0.911 & 0.087 & 2.82 & 14 & 0.889 & 0.092 & 1.81 \\
\hline 7 & 0.906 & 0.105 & 1.58 & 15 & 0.934 & 0.088 & 3.49 \\
\hline 8 & 0.960 & 0.098 & 3.25 & 16 & 0.948 & 0.094 & 3.34 \\
\hline
\end{tabular}

수록 S/N ratio를 커지게 하기 위해 음수를 취한다. ${ }^{8)}$

$S /$ Nratio $=-10 \log \left[\frac{1}{n} \sum_{i=1}^{n} \gamma_{i}^{2}\right]$

where n: Number of characteristics, Үi: Measured characteristics

$\mathrm{NH}_{3}$ 전환효율을 극대화하기 위해 최대 $\mathrm{NH}_{3}$ 농도 균일도와 활성시간 $\left(\mathrm{NH}_{3} \mathrm{UI} 0.82\right)$ 을 특성치로 정하 고, 이 값에 대한 비율을 무차원화시켜 최적 수준을 산출하였다(Table 4, Fig. 7 참조). 한편, 신뢰도 $95 \%$ (유의수준 $5 \%$ ) 수준에서 분산분석을 수행한 결과, $\mathrm{p}$-value가 0.05 보다 작은 설계인자는 분사방향(B)과 분사위치 $(\mathrm{C})$ 였으며, 모든 값이 유의수준에 근사하 였다(p-value $\mathrm{A}>0.05>\mathrm{B}>\mathrm{C}$ ). 여기서 설계인자 $\mathrm{A}$ 는 모든 조건에서 동일한 유량이 확보되도록 설정 함으로써 유의수준에서는 벗어났으나, 설계인자 및 수준은 타당하다고 판단된다.

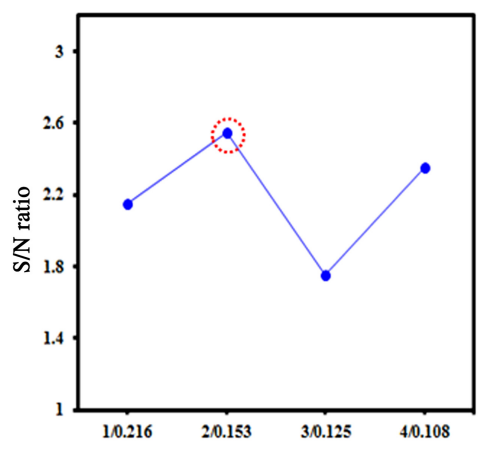

(a) Nozzle hole number/diameter [mm]

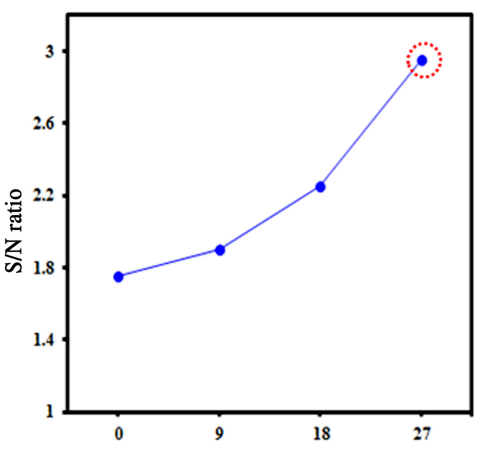

(b) Injection direction $\left[{ }^{\circ}\right]$

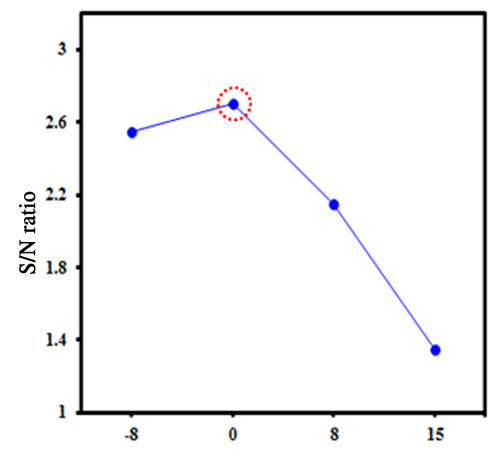

(c) Injection position [mm]

Fig. 7 Mean of $\mathrm{S} / \mathrm{N}$ ratio and optima of design variables (circles) 


\section{4 최적 수준 검증}

산출된 최적해를 Urea-SCR 촉매전단에 적용하여 $\mathrm{NH}_{3}$ 전환효율을 산출한 후, 초기모델과 비교하여 기존 대비 개선효과를 검증하였다. Fig. 8은 최적모 델과 초기모델의 유동접촉면을 비교한 것이다. 최 적모델은 초기모델 보다 유동접촉면의 크기(Land size)가 작고, 위쪽에 위치(Land position)하기 때문에 가수분해 및 열분해 반응이 일찍 발생한다. 따라서 벽류 발생을 현저히 감소시키면서, $\mathrm{NH}_{3}$ 전환시간도 충분히 확보할 수 있다. Fig. 9는 최적모델과 초기모 델의 최대 $\mathrm{NH}_{3}$ 농도균일도와 활성시간( $\left.\mathrm{NH}_{3} \mathrm{UI} 0.82\right)$ 을 비교한 것이며, 각각 기존대비 $15.5 \%, 37.2 \%$ 향 상되었다.

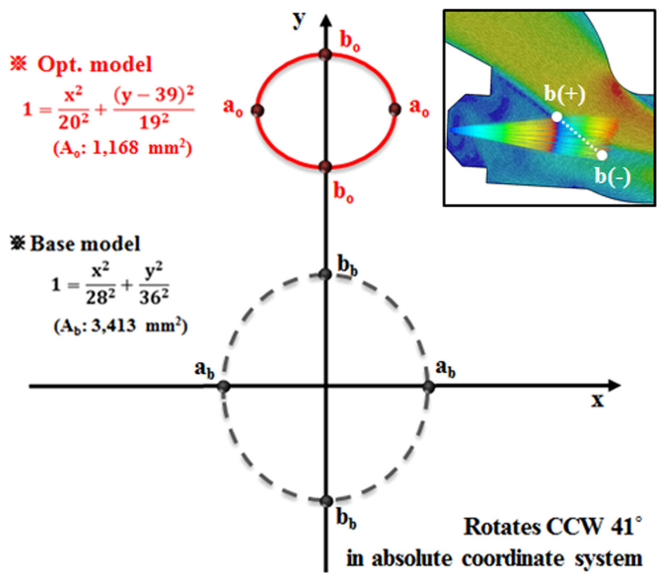

Fig. 8 Comparison of flow contact area between exhaust gas and UWS spray (Optimal vs. Base)

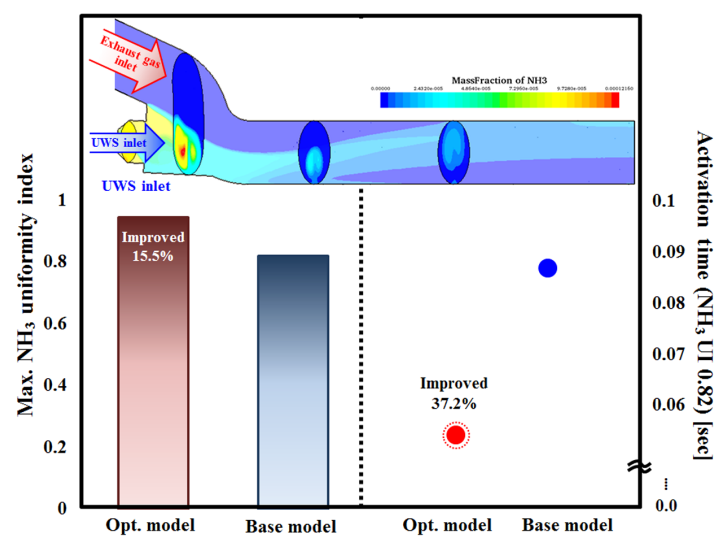

Fig. 9 Comparison of conversion efficiency of $\mathrm{NH} 3$ between optimal and base in front of SCR

\section{4. 벽류 최소화}

고화된 Urea에 의한 노즐 막힘을 고려하여 믹서 장착 및 시행착오법을 통해 벽류를 최소화시키는 방법을 제안한다.

\section{1 믹서 장착}

Urea 인젝터는 일반적으로 고화된 Urea에 의해 노즐이 막히면서 고장이 발생할 수 있다. 따라서 고 체 Urea의 축적을 수치적으로 예측하여 이를 방지 해야 하지만, 현재까지 이러한 프로그램은 전무한 상태이다. 본 연구에서는 STAR-CCM+7.06의 Fluid film 설정을 통해 고체 Urea 축적위치를 대략적으로 예측하고 이를 최소화시키는 방법을 제안한다. 최 적모델의 믹서 장착 유무에 따른 분무유동해석을 수행한 결과, 믹서 장착 모델의 Fluid film thickness 는 미장착 모델 대비 약 $98 \%$ 감소하였다(Fig. 10 참 조). 그리고 분무유동특성을 분석한 결과, 믹서 장착 모델은 믹서에 의해 증가된 유속으로 인해 복잡한 와류가 형성되었으며, 이로 인해 미장착 모델 대비 $\mathrm{NH}_{3}$ 농도균일도가 약 $4 \%$ 높게 산출되었다. 즉 믹서 장착에 의해 배기가스에 합류한 Urea 수용액의 가 수분해 및 열분해 반응이 더욱 촉진될 수 있음을 확 인하였다(Fig. 11, Fig. 12 참조).

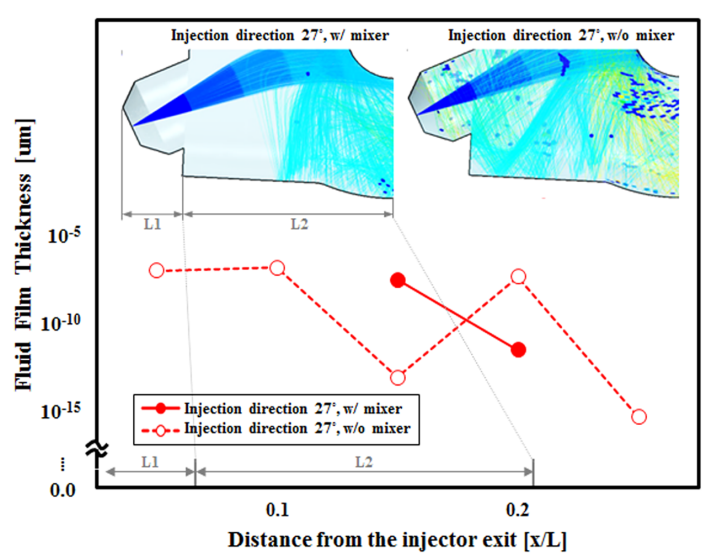

Fig. 10 Comparison of mean average of fluid film thickness between with mixer and without mixer in front of mixer $\left(\mathrm{L}_{1}-\mathrm{L}_{2}\right.$ section $)$

\section{2 시행착오법}

Urea-SCR 촉매전단의 전산모사를 통해 Fig. 13 과 


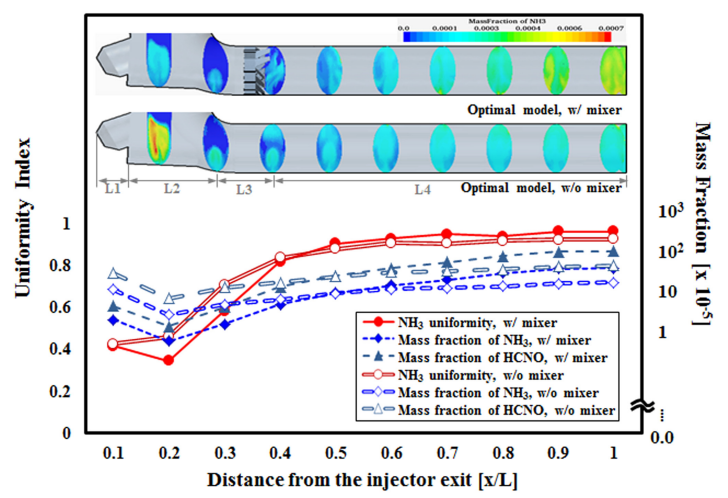

Fig. 11 Calculation results of $\mathrm{NH}_{3}$ uniformity index and mass fraction $\left(\mathrm{NH}_{3}, \mathrm{HCNO}\right)$ in front of $\mathrm{SCR}(\mathrm{w} /$ mixer vs. w/o mixer)

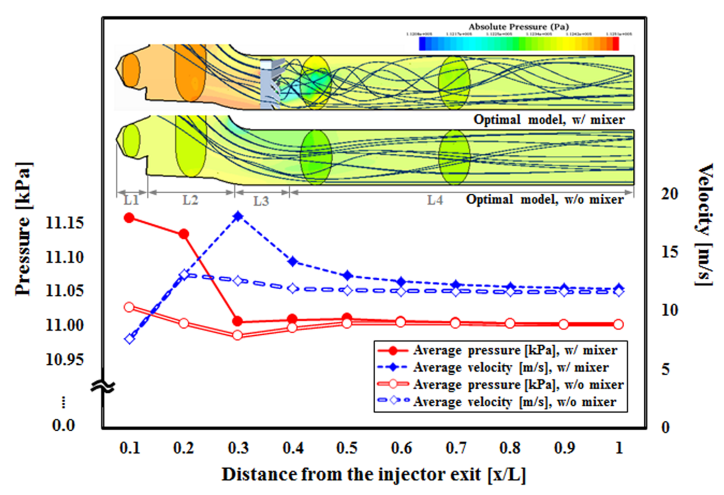

Fig. 12 Calculation result of pressure and velocity in front of SCR

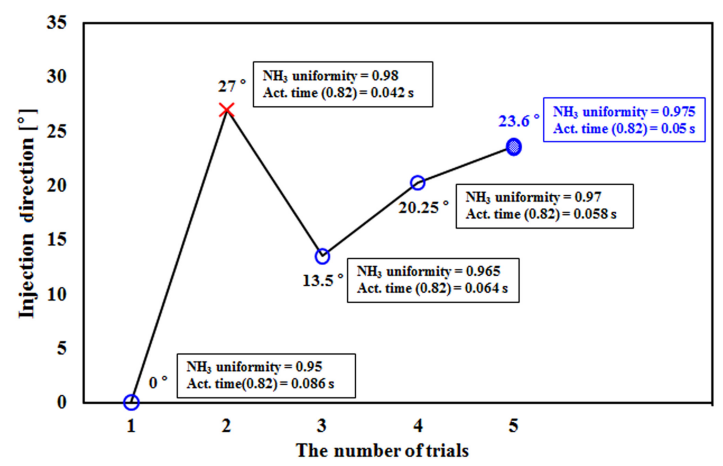

Fig. 13 The results of trial and error method

같이 총 5 차례의 시행착오를 수행하여, Urea 인젝터 의 분사방향을 보정하였다. 그 결과 Urea 인젝터 주 변에는 벽류가 거의 발생하지 않았으며, $\mathrm{NH}_{3}$ 전환 효율이 가장 높은 분사방향은 $23.6^{\circ}$ 로 산출되었다.

\section{5. 결 론}

본 연구에서는 Urea 인젝터의 주요 설계변수를 최적화하기 위해, $\mathrm{L}_{16}$ 직교배열(3인자-4수준)에 의 한 실험계획법(DOE)과 다구치 법의 망소특성으로 최적수준을 결정하였다. 그리고 고화된 Urea에 의한 노즐 막힘을 최소화시키기는 방안을 제안하였다.

1) 전술한 방법으로 최적수준을 산출하여, 최적모 델과 초기모델의 유동접촉면을 비교한 결과, 최 적모델의 유동접촉면 위치는 위쪽으로 약 $17 \mathrm{~mm}$ 상승하였고, 크기는 $1 / 3$ 이상 감소하였다. 그리 고 최대 $\mathrm{NH}_{3}$ 농도균일와 활성시간( $\left.\mathrm{NH}_{3} \mathrm{UI} 0.82\right)$ 은 각각 $15.5 \%, 37.2 \%$ 향상되었다.

2) 고화된 Urea에 의한 Urea 인젝터의 고장을 최소 화시키기 위하여, 믹서 장착 및 시행착오법을 통 한 분사각도 수정을 제안하였다. 검증 결과, 초기 모델 대비 최대 $\mathrm{NH}_{3}$ 농도균일도와 활성시간 $\left(\mathrm{NH}_{3}\right.$ UI 0.82 )은 각각 $19.5 \%, 41.9 \%$ 향상되었다.

\section{후 기}

본 연구는 산업통상자원부 주관 “클린디젤자동 차핵심부품육성사업(R0000703)”의 일환으로 수행 되었으며, 관계자분들께 진심으로 감사드립니다.

\section{References}

1) P. Eastwood, Critical Topics in Exhaust Gas After-treatment, Research Studies Press, Baldock, 2000.

2) S. J. Jeong, S. J. Lee, W. S. Kim and C. B. Lee, "Numerical Study on the Injector Shape and Location of Urea-SCR System of Heavy-duty Diesel Engine for Preventing $\mathrm{NH}_{3}$ Slip," Transactions of KSAE, Vol.14, No.1, pp.68-78, 2006.

3) F. Birkhold, U. Meingast and P. Wassermann, "Modeling and Simulation of the Injection of Urea-water-solution for Automotive SCR DeNOxsystems," Appl. Catal. B: Environ., Vol.70, No.1-4, pp.119-127, 2007.

4) S. J. Jeong and C. H. Lee, "A Study on the Injection Characteristics of Urea Solution to Improve deNOx Performance of Urea-SCR Catalyst in a Heavy Duty Diesel Engine," 
Transactions of KSAE, Vol.16, No.4, pp.165$172,2008$.

5) J. M. Oh, K. H. Lee and J. H. Lee, "A Study on the Optimal Injection Conditions for an HCLNT Catalyst System with a 12-Hole Type Injector," Journal of Thermal Science and Technology, Vol.3, No.2, pp.278-291, 2008.

6) H. Storm, A. Lundstrom and B. Andersson, "Choice of Urea-spray Models in CFD Simulations of Urea-SCR Systems," CEJ 's, Vol.150,
Issue 1, pp.69-82, 2009.

7) T. H. An, S. Y. Lee and M. Y. Kim, "Numerical Analysis on the Evaporation and Mixing Characteristics of Urea Water Solution in the Urea-SCR System," KSME, No.11, pp.12231228, 2012.

8) G. Taguchi, "Introduction to Quality Engineering: Designing Quality into Product and Processes," Asian Productivity Organization, pp.1-191, 1988. 